\title{
An Opinion Poll for the Establishment of a Bioethanol Plant Utilizing Local Resources and a Fuzzy Inference System
}

\author{
Michael N. Tsatiris \\ Department of Forestry and Management of the Environment and Natural Resources, Democritus University of Thrace, Orestiada \\ 68200, Greece
}

\begin{abstract}
The cultivation of sweet sorghum (sorghum bicolor) is still one of the new promising energy crops for bioethanol production nowadays. An opinion poll for the establishment of a bioethanol plant utilizing local resources such as the cultivation of sweet sorghum and the zeolite deposits was held. Data were collected by heads of selected households of the Municipality of Trigono (Evros, Greece). The simple random sampling was applied and a face-to-face interviewing and filling in of the forms of a questionnaire was conducted. It was estimated that some 44,778-55,971 acres of land should be cultivated with sweet sorghum for a satisfactory production of bioethanol in a bioethanol plant in the order of 120,000-150,000 tons/year. Furthermore, in this paper an optimum solution was estimated by using of the Fuzzy Logic Toolbox of Matlab (Intelligent system) which is formulated as follows "the bioethanol plant absorbing the sweet sorghum's production of a cultivating area of 46,600 acres and operating 12 hours/day would produce 125,000 tons of bioethanol annually". Such a vast area of land would offer occupation to a significant number of young farmers for the cultivation of sweet sorghum.
\end{abstract}

Key words: Opinion poll, sweet sorghum, clinoptilolite, bioethanol's plant, fuzzy logic.

\section{Introduction}

\subsection{Bioethanol's Production, Sweet Sorghum and the} Study's Area

The European Parliament, by creating the instruction 2003/30/EC/08.05.03 relative to the promotion of biofuels or other renewable fuels for transport usage, summoned all the European Union members to substitute conventional fuels. So, all the members of the Union are obliged to use biofuels at the minimum percentage of $5.75 \%$ until 2010, which in Greek standards is corresponded to an annual production of 390,000 tons of bioethanol [1].

The country which is already considered to be successful in replacing the conventional fuels with biofuels is Brazil whose efforts in bioethanol production, which was supposed to replace the oil are

Corresponding author: Michael N. Tsatiris, assistant professor, Ph.D., main research fields: biomass and bioenergy. E-mail: tsatiris@fmenr.duth.gr. considered to be absolutely successful. An $80 \%$ of the new automobiles in the country has the ability to use a gasoline and ethanol mixture, while a percentage of more than $20 \%$ of the whole number of the means of transport uses bioethanol exclusively [2, 3].

Bioethanol in Brazil is produced by using sugar cane as a plant raw material, in the USA by using corn and in France by using wheat and sugar beet [4]. In Greece there is no bioethanol production currently as a biofuel for automobiles [3].

For the production of bioethanol the agricultural plants which can be used are the sugar beet, the sugar cane, the corn, the wheat and sweet sorghum [5]. The last one which is an annual crop gave unexceptionable results in the experimental cultivations which took place in North Greece and in Kopaida region. Its output in sugar is remarkable and it is characterized by a high photosynthetic ability contributor, high biomass yields potential and a high percentage of easily 
fermentable sugars. In the Table 1, the output in biomass and bioethanol per acre of the above mentioned plants is shown [1].

One of the most remarkable ideas for biofuel production in Greece is the establishment of an industrial unit of bioethanol production in the municipality of Trigono in Evros prefecture, which is going to use sweet sorghum as a plant raw material.

The municipality of Trigono is located in Evros prefecture. According to the census of 2011, the population of the municipality consists of 6,656 habitants and its size is $128,913.58$ acres [6]. It is the northernmost municipality of Greece as it is located above the Ardas River among Greece, Turkey and Bulgaria. The economy of the municipality is mainly based on agriculture. The usual cultivations are corn, cotton and wheat as well as other cultivations in less extent. The problems in agriculture did not let the area unaffected. The population of the municipality has been decreased through the last years.

The authors believe that the establishment of a bioethanol production industrial unit which will use sweet sorghum as a plant raw material will comprise respiration for the greater region of Evros prefecture because apart from the biofuel production, the cultivation of sweet sorghum which will probably be well bounded, will provide economic motives to the planters of the area, support the agricultural economy and sustain the population in the countryside.

\subsection{Zeolite (Clinoptilolite)}

Zeolites (Greek, zein, "to boil"; lithos, "a stone") are minerals that have a porous structure. The term was originally coined in the 18th century by a Swedish mineralogist named Axel Fredrick Cronstedt who observed, upon rapidly heating a natural mineral that the stones began to dance about as the water evaporated. Using the Greek words which mean "stone that boils," he called this material zeolite. More than 150 zeolite types have been synthesized and 48 naturally occurring zeolites are known. They are
Table 1 Output in biomass and bioethanol per acre of some agricultural plants [1].

\begin{tabular}{lll}
\hline Energy crops & $\begin{array}{l}\text { Biomass } \\
\text { tones/acre }\end{array}$ & $\begin{array}{l}\text { Bioethanol } \\
\text { litres/acre }\end{array}$ \\
\hline Sweet sorghum & $28-32$ & 2,680 \\
Corn & 4 & 1,600 \\
Sugar beet & 26 & 2,320 \\
Wheat & 1.6 & 560 \\
\hline
\end{tabular}

basically hydrated alumino-silicate minerals with an "open" structure that can accommodate a wide variety of positive ions, such as $\mathrm{Na}^{+}, \mathrm{K}^{+}, \mathrm{Ca}^{2+}, \mathrm{Mg}^{2+}$ and others. These positive ions are rather loosely held and can readily be exchanged for others in a contact solution $[7,8]$.

The important part of the Natural Zeolite is the crystalline hydrated alumino-silicate of alkaline metals and metals of alkaline earths $(\mathrm{Ca}, \mathrm{K}, \mathrm{Na}, \mathrm{Mg})$ called Clinoptilolite which is found in Petrota and Pentalofos of the municipality of Trigono (Evros, Greece) (Fig. 1). This zeolite deposit is of a great economic interest, considering that it is the richest among the zeolite formations in North-eastern Greece $\left(4.7 \times 10^{6}\right.$ tons $)[9,10]$.

Clinoptilolite is a $100 \%$ natural nutrient and water management system that promotes [12-14]:

(a) Lower fertilizer cost and water conservation, (b) Improved plant "yields", growth in poor, sandy and porous soils, (c) Balanced pH (7.0) and aerated soil, (d) Proven soil buffering and encapsulation of: (d1) Noxious gases preventing root decay, (d2) Toxic chemicals, hydro carbons heavy metals and salts. Clinoptilolite improves the efficiency of used fertilizers and thus promotes better plant growth and consequently enhances the yield. Clinoptilolite added to fertilizers helps to retain nutrients and, therefore, the long term soil quality is improved, enhancing its absorption ability. It concerns the most important plant nutrients such as nitrogen $(\mathrm{N})$ and potassium $(\mathrm{K})$, and also calcium, magnesium and micro-elements.

Clinoptilolite is used successfully in the cultivation of a wide variety of crops including cereals, vegetables, grapes, other fruits and sorghum [15]. 


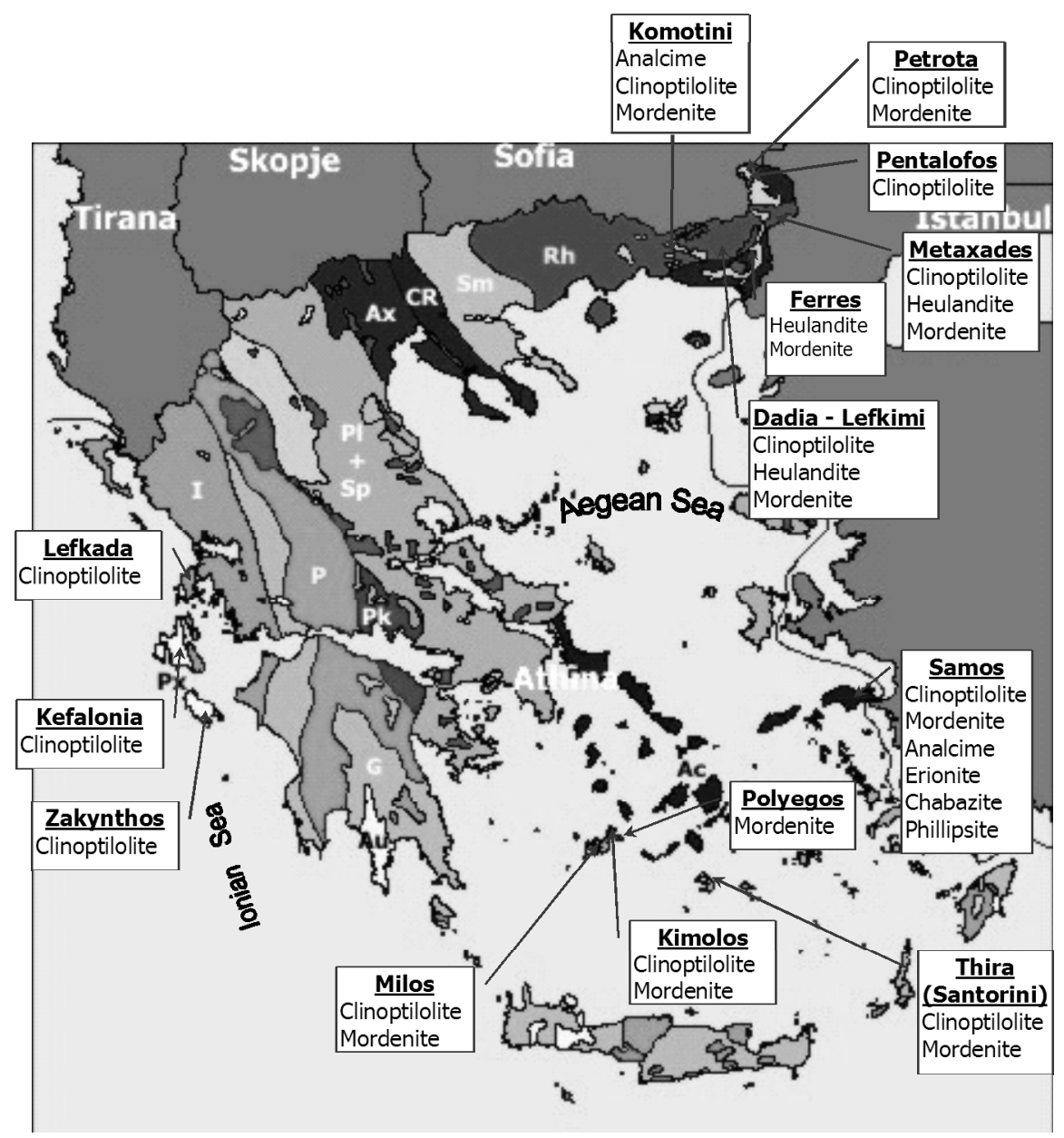

Fig. 1 Existence's areas of clinoptilolite deposits in Greece [11].

Clinoptilolite, which is found in Petrota and Pentalofos of the municipality of Trigono could be utilized as a soil ameliorative for cultivation of sweet sorghum which is going to be used as a raw material for bioethanol production in the above mentioned area.

\subsection{The Aim of the Study}

An opinion poll for the establishment of a bioethanol plant utilizing local resources such as the cultivation of sweet sorghum and the zeolite deposits was held. In this paper the views of the inhabitants of the Municipality of Trigono (Evros, Greece) related to the cultivation of sweet sorghum as a plant raw material for bioethanol production in this area, the utilization of zeolite (clinoptilolite) as a natural soil ameliorative for the cultivation of sweet sorghum as well as the contribution of this bioethanol plant to the local development are investigated. Furthermore, in this paper the optimum solution of the annual bioethanol production at a bioethanol plant in relation to the cultivating area with sweet sorghum and to the time of plant operation is estimated by using of the Fuzzy Logic Toolbox of Matlab (Intelligent system).

\section{Methodology}

\subsection{Determination of the Sample Size}

The municipality of Trigono consists of 2,684 households [6]. The formula of simple random sampling without repetition (Eq. (1)) was applied to estimate the sample's size (n) with given accuracy and minimum cost for the "population" of the municipality of Trigono [16-19]: 


$$
n=\frac{N * t^{2} * s^{2}}{N * d^{2}+t^{2} * s^{2}}
$$

Where,

n: size of sample;

d: absolute error;

S: standard deviation;

$2,684=\mathrm{N}$ : the number of households of the municipality of Trigono or the size of the "population".

$2.021=\mathrm{t}$ : the value of STUDENT distribution for probability $(1-\mathrm{a}) \%=95 \%$ and $\mathrm{n}-1 \cdot(41-1=40)$ degrees of freedom.

The unknown parameters $d$ and $s$ (Eq. (1)) were estimated with the help of a pilot sampling [20], where a pilot sample of 41 households-observations was randomly taken by the municipality of Trigono.

Particularly, the quantitative variable "mean annual production of agricultural products per household" which presents the largest standard deviation regarding the mean (a borderline case) was selected and then the standard deviation of this variable was used in the above formula (Eq. (1)) as a standard deviation (S). The characteristic values of the variable were:

$\mathrm{x}($ mean $)=35.42$ tons of agricultural products per household and year and $\mathrm{s}=7.61$ tons of agricultural products per household and year. The absolute error (d) or the estimation's accuracy was taken as being equal to $2 \%$ of the population mean, namely $\mathrm{d}=0.02 \times$ 35.42 or $\mathrm{d}=0.708$.

So, the sample's size (n) was estimated in Eq. (2):

$$
\begin{gathered}
n=\frac{2,684 *(2.021)^{2} *(7.61)^{2}}{2,684 *(0.708)^{2}+(2.021)^{2} *(7.61)^{2}} \\
\mathrm{n}=402 \text { households. }
\end{gathered}
$$

\subsection{Choice of Households and Conduct of the} Sampling Research

The 402 households of the sample were then precisely located (full name and address) by using random numbers on the consumers' lists of domestic electric current.

Sampling frame refers to the set of all possible sample units [21-23]. The lists of consumers of domestic electric current were used as a sampling frame in the case of this research. These lists were preferred, because they were more complete and more informed than those of other services, for example phone book, municipal rolls.

Tables of random numbers and the method of simple random sampling without repetition were used for the choice of simple random sample [17]. Thus, all selected households (regular households) in the sample are different at each other, namely each selected household is taken in the sample only once. Each selected regular household was determined in these lists by the corresponding full name and address.

Surrogate households besides were taken because "deniers" would result at the conduct of sampling research. The quantity of surrogate households was taken equal to $30 \%$ of the sample size $[21,22]$. Tables of random numbers were used for the choice of surrogate households [17]. Each selected surrogate household was determined in these lists by the corresponding full name and address.

In all selected households (regular and surrogate), registered letters were sent by which the aim of this research is explained and the date and time at which the interviewer will meet the interviewee in the place of residence of the last one are predetermined [22, 23]. In other words, the conduct of sampling research with the realization of face-to-face interviewing between the researcher and the heads of selected households and filling in of the forms of a questionnaire was decided.

The number of households that were selected through the lists of consumers of domestic electric current is 402 regular households and 121 surrogate households.

Afterwards the realization of the first phase of face-to-face interviews, the total "refusals" came to $6.4 \%$ of the initially selected households. These 
"refusals" due mainly to direct refusals (refusal for interview) and to absentees. In second phase, the void that resulted from the "deniers" was covered with the realization of face-to-face interviews in surrogate households which had been selected for this purpose.

The relatively large quantity of the required for gathering information and the possibility of direct clarification of questions contributed in the appointment of face-to-face interviewing as the most reliable and suitable technique of information collection in this case, although that the face-to-face interviews were expensive in money and time, where it concerned in the time of locomotion, approach of the area of research and interview of the respondents. With the method of face-to-face interviewing, a relatively high percentage of response from the side of the respondents was achieved, fact which would not happen through the postal returned questionnaire survey, if the authors furthermore count in the educational level particularly in the case study of rural population $[24,25]$.

Four hundred and two forms of the questionnaire totally were filled in. After the gathering of 402 forms of the questionnaire, control of these forms took place. A small number of individual questions were unanswered and were considered as invalid.

\subsection{Control of the Forms of the Questionnaire}

After the gathering of forms of the questionnaire, they were controlled for the detection of by any chance serious lacks. This control aimed at the ascertainment of completeness, consequence and plausibility of the answers in the forms of the questionnaire [22, 24]. The control of completeness aims at the ascertainment of by any chance unanswered questions. The control of consequence becomes through the questions of indirect control by which the by any chance inconsequence of the respondent in questions that measure the same characteristic is ascertained. The control of plausibility aims at the revelation of logical consequence at the answers that are given and it becomes with the comparison of answers in proportional relative questions of the questionnaire [22]. The analysis of the data was carried out by using the Excel program for Windows.

\subsection{Solving a Problem by Using the Fuzzy Logic Toolbox of Matlab (Intelligent System)}

Given two sets of numbers, the first one between 0 and 56,000 acres and the second one between 0 and 24 hours that respectively represent the cultivating area with sweet sorghum and the time of plant operation at a bioethanol plant. What should the annual production of bioethanol be? The Fuzzy Logic Toolbox of Matlab was used to solve this problem.

\section{Results and Discussion}

\subsection{Contribution of a Bioethanol Production Plant to the Local Development}

The analysis of the data which were collected by a sample's size of 402 households by the municipality of Trigono, showed the planters' great dissatisfaction which comes from the bounties of their products, the country's agrarian policy as well as their discomposure due to the fact that young people do not work in agriculture and seek other ways to survive which has as a consequence the gradual depopulation of the countryside.

The majority of those who were asked (74\%) believed that the young people abandon agriculture mainly due to the lack of economic amplifications and facilitations as well as the lack of vision which will give them motivation to turn to this specific sector. This can be tangible from the fact that the $74 \%$ of those who were asked is minded in turning its tillage into sweet sorghum having the conviction that profit will come out of this change.

In the question relative to the income from the cultivation of sweet sorghum, comparably to any other agricultural plant, $81 \%$ believes that it will rise while $2 \%$ believes that it will be decreased and the rest $17 \%$ 
believes that it will remain immutable. The divergence of the percentage between those who believe that their income will rise from the change of their tillage (81\%) and those who are really minded to change it (74\%), due to several factors such as the difficulty of convincing the demands of the new tillage.

Despite the fact that the above mentioned data are encouraging for the establishment of a bioethanol production industrial unit in the municipality of Trigono, a prominent percentage of those who were asked, encounters this issue with great wariness. In the question relative to the public's opinion about the possibility for this industrial unit to be constructed, the negative answer prevails with a percentage of $59.3 \%$ over the positive answer which touches the percentage of $25.6 \%$. The rest $15.1 \%$ chose not to answer this question. This great negative percentage can be partly justified because of the dissatisfaction and disbelief that has been caused to the agrarian population because of the way in which the state takes care of the agrarian issues especially in borderlands.

At the percentage of $68 \%$ those who were asked had been informed for the establishment of a bioethanol production industrial unit by the local authorities and at the percentage of $30.5 \%$ by fellow-villagers. The rest percentage had been informed in different ways. The municipality of Trigono provides to young and new planters agrarian seminars which are relative to the cultivation of sweet sorghum. All the above mentioned information shows the mobilization of the local authorities in order to inform those who are interested in cultivating of sweet sorghum for the operation of this specific industrial unit.

In the question relative to the contribution of this unit to local development, $80.7 \%$ of those who were asked, believed that this unit will constitute an important attraction pole for incoming planters considering the fact of the reduced taxes which will be paid by those who will take part in the bioethanol production program, the relatively higher bounties and the capability of the unit to employ to a large part of the area's population. Besides, it is a common conviction that the unit will become an attraction pole for the youth who left the area because of the lack of occupation. This is based on the fact that the unit will be able to absorb the total amount of the sweet sorghum production of a cultivating area that reaches at the most 55,971 acres. It was estimated that 44,778-55,971 acres of land should be cultivated with sweet sorghum for a satisfactory production of bioethanol in a bioethanol plant in the order of $120,000-150,000$ tons/year. It is clear that such a vast area of land is needed which would offer occupation to a significant number of young farmers for the cultivation of sweet sorghum.

Moreover, in order to inform the people interested, the mobilization of a responsible bureau or agency is required, so that they participate in their majority in the bioethanol production program through the cultivation of the sweet sorghum. One such effort would be considered enough to attract younger people into farming with a direct result to bring them back to the countryside.

Specifically, regarding the question "what biofuels do the planters know"-including wood, agricultural by-products, bioethanol and biodiesel—wood prevailed $(100 \%)$ over the others because it constitutes the simplest and most familiar renewable energy source. The agricultural by-products are known at a percentage of $85 \%$, while only $23 \%$ of those who were asked were aware of what bioethanol is and $6 \%$ of them knew about biodiesel.

\subsection{The Utilization of Zeolite of the Municipality of Trigono as a Soil Ameliorative for Sweet Sorghum's Cultivation for Bioethanol's Production}

The average age of the people who were questioned was between the age of 50 to 65 years old (54\%). This percentage can go as high as $63 \%$ for the total of people over 50 years old (Fig. 2). This is due to the fact that the municipality of Trigono is located in an 
area where the main occupation of the inhabitants is agriculture. Furthermore, young people prefer to move to cities and find employment there than work in the fields as farmers. This situation is caused because of the fact that there are no financial advantages or benefits and the lack of vision or any form of motivation from the state to help them stay and work in the agricultural sector.

The majority of those who were asked (92\%) were well aware of the fact that there are zeolite deposits in Trigono. This is a proof that the residents of this area are interested and well-informed about the natural resources which are present in their area and can be used in many industrial sectors. $72 \%$ of the respondents were aware of the excavation program of zeolite (clinoptilolite) in the area of Petrota, due to the fact that it is a small community and the locals can get informed relatively easily about what is taking place in their county (Fig. 3).

It is worth noticing that the majority of the subjects (respondents) were familiar with the beneficial properties of using clinoptilolite as a soil ameliorative

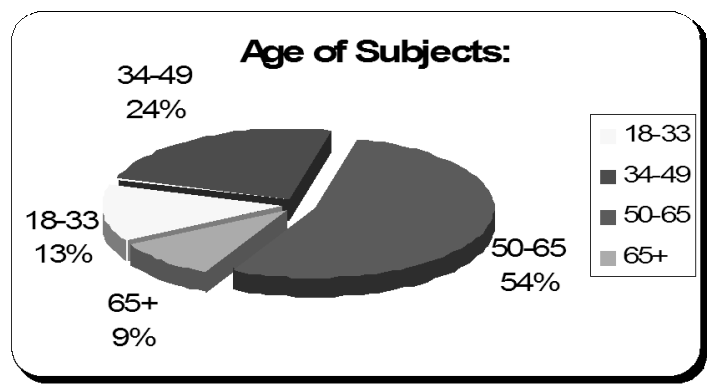

Fig. 2 Age of subjects.

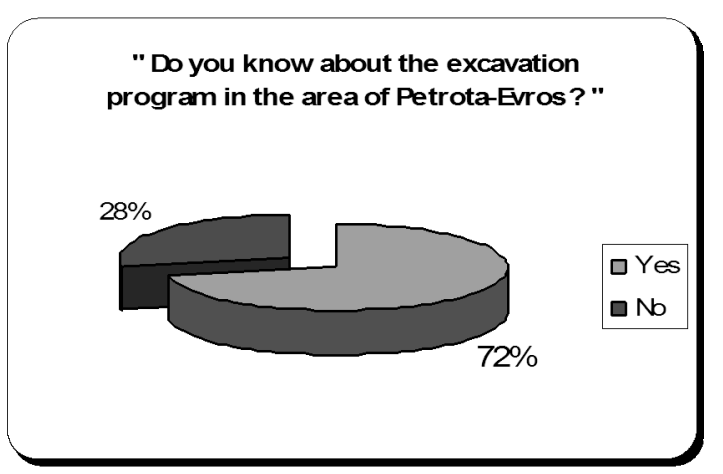

Fig. 3 Knowledge of the respondents for the excavation program of clinoptilolite in the area of Petrota-Evros. (one of its uses). Meanwhile, approximately $78 \%$ of them are willing to use clinoptilolite in their crops and specifically in the cultivation of sweet sorghum, if there is encouragement of its production by the state (Fig. 4). All of them (78\%) expect a higher yield in their crops as a direct result of the use of this particular ameliorative.

There were six different answers regarding the question about the means of information for the beneficial properties of clinoptilolite as a soil ameliorative. Most people were notified by the Agricultural Cooperative (38\%), many by the Local Prefecture (31\%) and quite a few by their fellow-villagers (25\%). It is important to mention that only a small percentage of the subjects (respondents) (a total of 6\%) were notified through the Mass Media (Radio-Television-Press) (Fig. 5).

Regarding the question on the uses of zeolite, most subjects (respondents) were familiar with two of its major applications: First, as a soil ameliorative for crops $(78 \%)$ and second as an animal feedstuff (32\%). Zeolite application as a greenhouse "bedding", as a

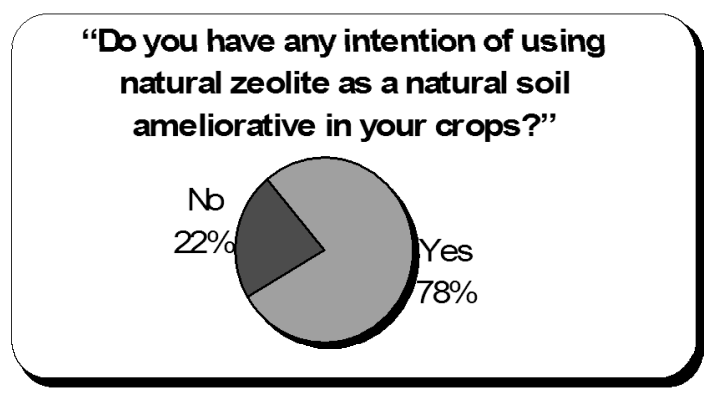

Fig. 4 Intention of subjects regarding usage of clinoptilolite as a soil ameliorative in crops.

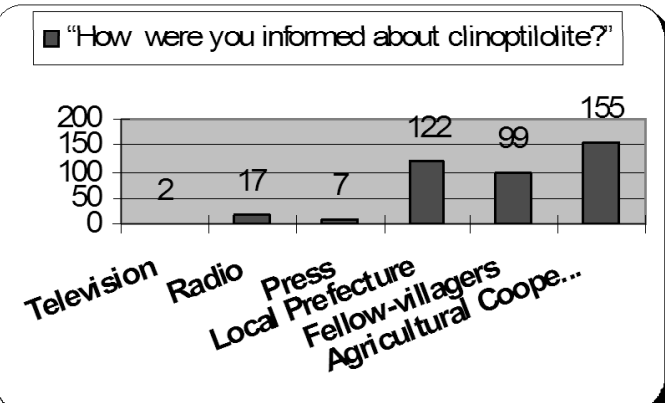

Fig. 5 Means of information about the beneficial properties of clinoptilolite as a soil ameliorative. 
mean for cleaning sewage, as an ameliorative for acidic soils and in the detergent industry are little known (13\%, 9\%, 7\% and 7\% respectively). The uses of clinoptilolite for the enrichment of oxygen as well as the purification of natural gas are almost unknown ( $2 \%$ and $1 \%$ respectively).

\subsection{Building of a Fuzzy Inference System}

\subsubsection{Fuzzy Approach}

The following 3 rules were set:

- If cultivating area with sweet sorghum is small and time of plant operation is part time, production of bioethanol is low;

- If cultivating area with sweet sorghum is medium, production of bioethanol is medium;

- If cultivating area with sweet sorghum is large or time of plant operation is full time, production of bioethanol is high.

The four basic steps for building and simulating of a fuzzy logic system are the following [26-30]:

(1) Defining inputs and outputs;

(2) Creating membership functions;
(3) Creating rules;

(4) Simulating the results of a fuzzy logic system.

3.3.2 1st Step-defining Inputs and Outputs

The mamdani method was selected in the FIS Editor. This problem has 2 input variables and 1 output variable. The input 1 variable is the "cultivating area with sweet sorghum". The input 2 variable is the "time of plant operation". The output variable is the "annual production of bioethanol" (Fig. 6).

3.3.3 2nd Step-creating Membership Functions

The membership functions for the 3 variables were defined, namely for the variables: "cultivating area with sweet sorghum", "time of plant operation", "annual production of bioethanol".

The gaussmf was selected as a type of membership function for the input 1 variable "cultivating area with sweet sorghum". The number of membership functions is 3 (small, medium and large). The range of "cultivating area with sweet sorghum" is between 0 and 56,000 acres (Fig. 7).

The trapmf (trapezoid membership function) was selected as a type of membership function for the

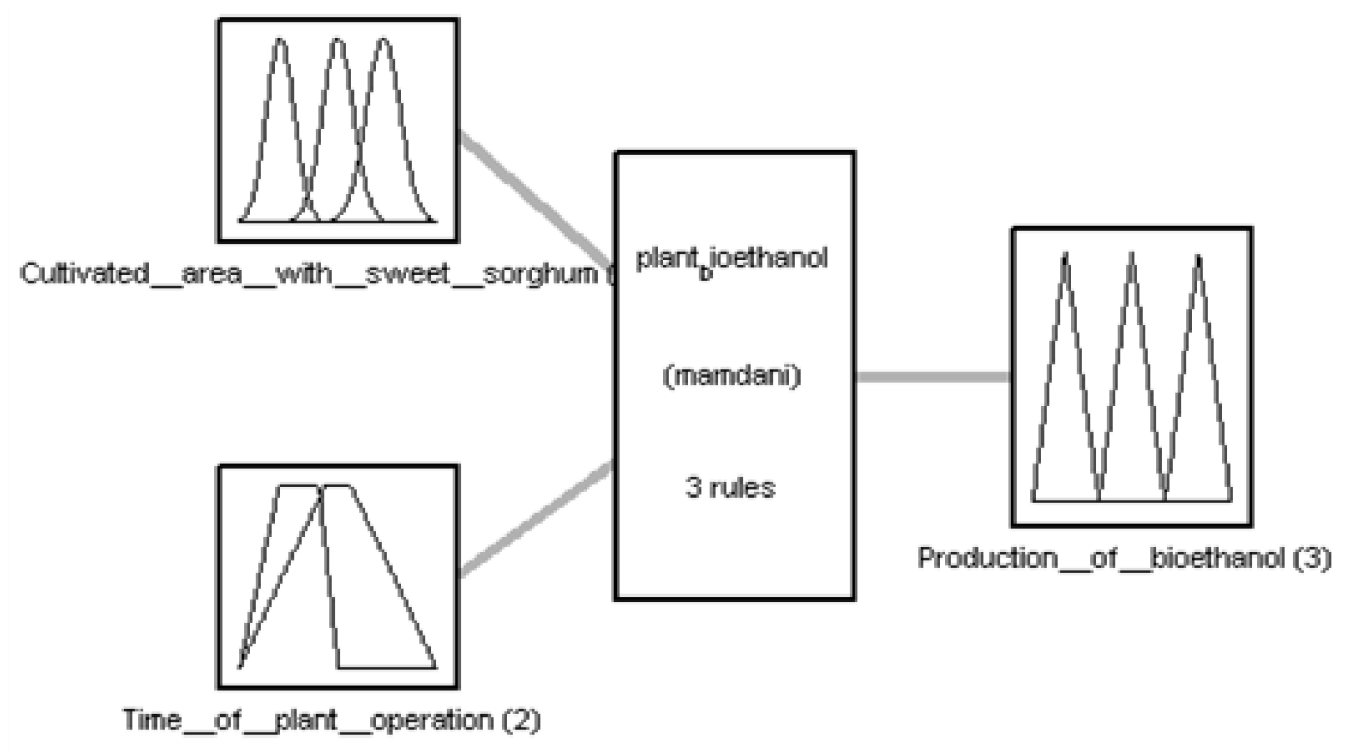

System plant, jioethanol: 2 inputs; 1 outputs; 3 rules:

Fig. 6 Defining inputs and outputs. 


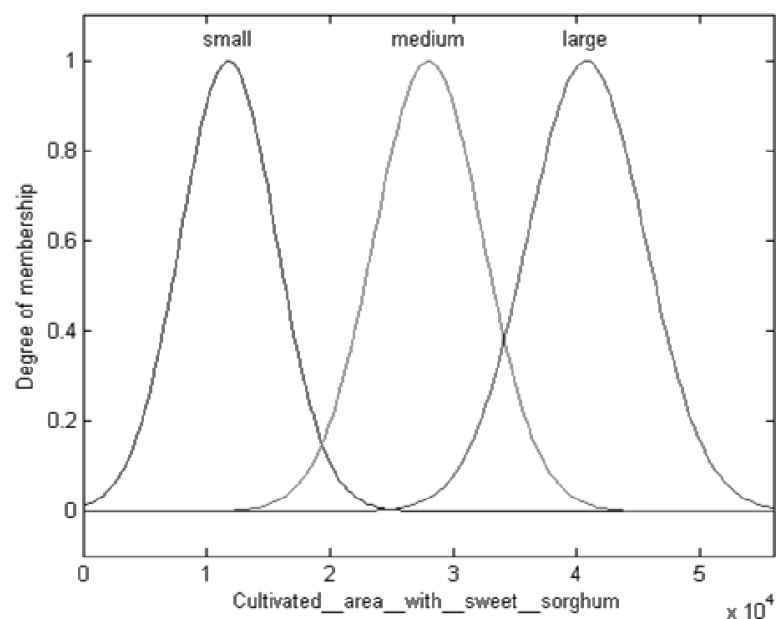

Fig. 7 The three membership functions (small, medium and large) for the input 1 variable "cultivating area with sweet sorghum".

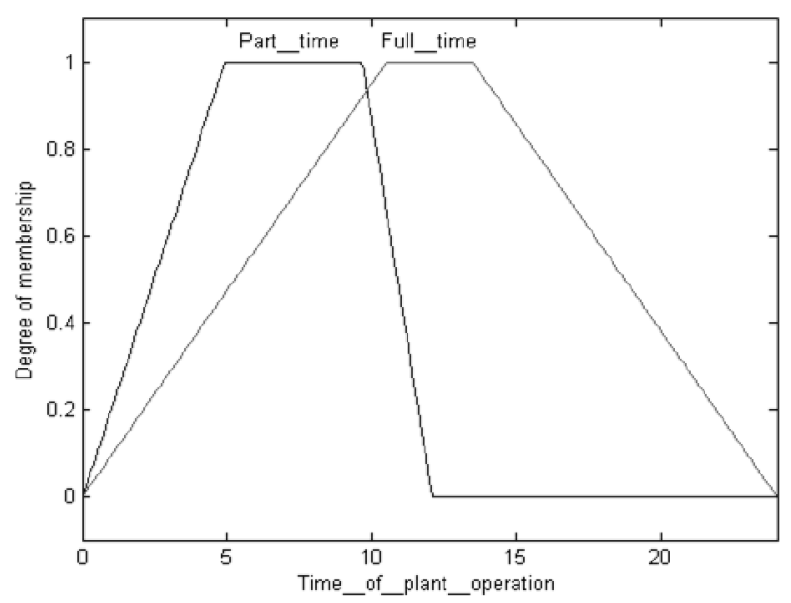

Fig. 8 The two membership functions (part time and full time) for the input 2 variable "time of plant operation".

input 2 variable "time of plant operation". The number of membership functions is 2 (part time, full time). The range of "time of plant operation" is between 0 and 24 hours (Fig. 8).

The trimf (triangular membership function) was selected as a type of membership function for the output variable "annual production of bioethanol". The number of membership functions is 3 (low, medium and high). The range of "annual production of bioethanol" is between 0 and 150,000 tons of bioethanol/year (Fig. 9).

\subsubsection{3rd Step-creating Rules}

Rule statements are constructed automatically in the

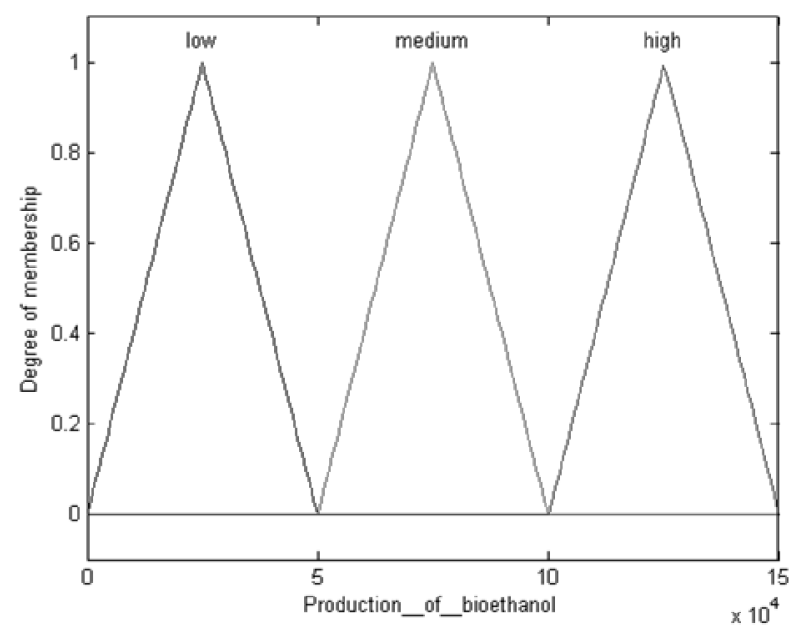

Fig. 9 The three membership functions (low, medium, and high) for the output variable "annual production of bioethanol".

Rule Editor. The 3 rules of fuzzy approach were added in the Rule Editor (Fig. 10).

3.3.5 4th Step-simulating the Results of a Fuzzy Logic System

The results of Rule Viewer (Fig. 11) and Surface Viewer (Fig. 12) of a fuzzy inference system are simulated and analyzed.

In the Rule Viewer (Fig. 11), each column shows a set of membership functions for a particular variable. 3 membership functions for "cultivating area with sweet sorghum" input 1 variable, 2 membership functions for "time of plant operation" input 2 variable and 3 membership functions for "annual production of bioethanol" output variable are presented in Fig. 11.

Each membership function in this set is associated with a particular rule and maps input variable values "cultivating area with sweet sorghum" and "time of plant operation" to rule input values. In other words, the number of rows here is the number of rules that the authors have. The first row corresponds to the first rule, the second row corresponds to the second rule and the third row corresponds to the third rule. The plots in the output column show how the rules are applied to the output variable. The bottom right plot shows how the output of each rule is combined to make an aggregated output and a defuzzified value. 


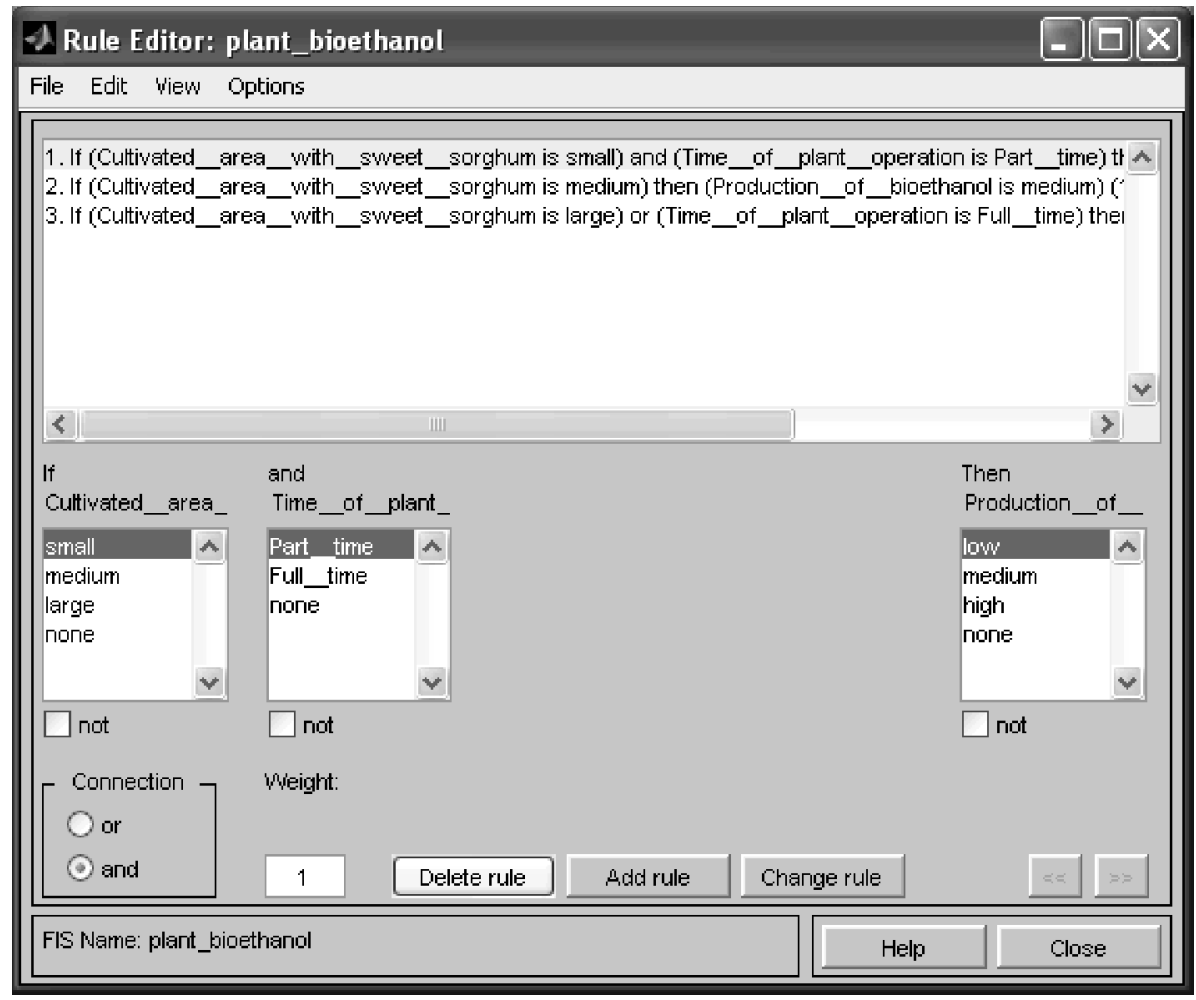

Fig. 10 The rule editor: the three rules are appeared in the up part of this window.

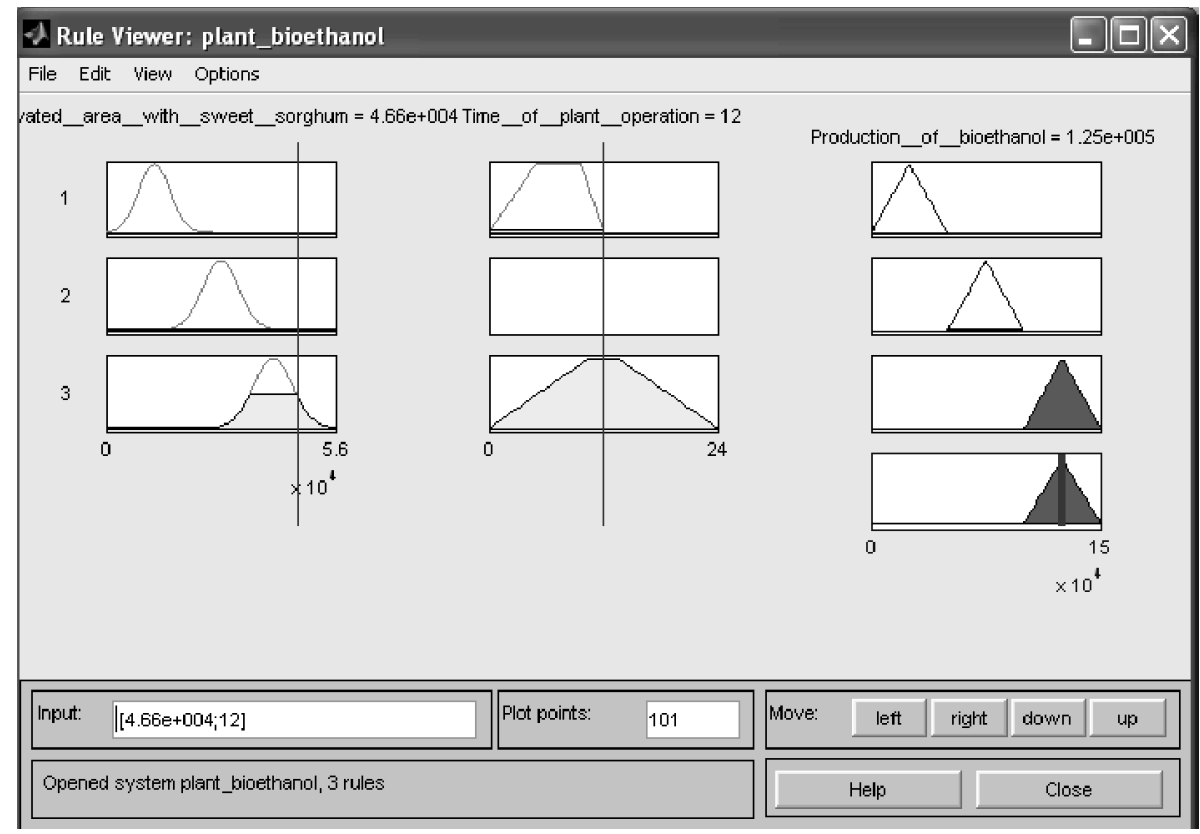

Fig. 11 The rule viewer.

The red line provides the defuzzified value for the annual production of bioethanol. The input value for "cultivating area with sweet sorghum" is 46,600 acres and the input value for "time of plant operation" is 12 hours and they correspond to an output value for "annual production of bioethanol" equal to 125,000 tons of bioethanol.

The Surface Viewer (Fig. 12) displays a surface that represents a mapping from the "cultivating area with sweet sorghum" and the "time of plant operation" to 


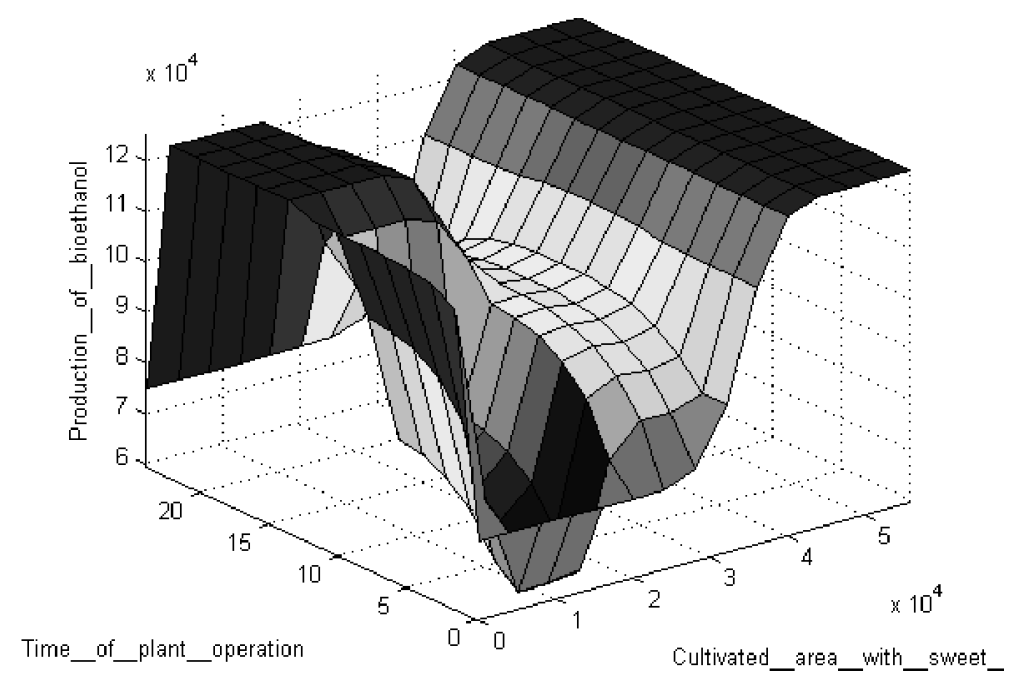

Fig. 12 The surface viewer: annual production of bioethanol as it is affected by the cultivating area with sweet sorghum and time of plant operation.

the "annual production of bioethanol". This shows a high value of annual production of bioethanol for large cultivating area with sweet sorghum and full time of plant operation, a low value of annual production of bioethanol for a small cultivating area with sweet sorghum and a part time of plant operation and a large flat area in the middle corresponding to a medium (average) annual production of bioethanol for medium cultivating area with sweet sorghum.

\section{Conclusion}

An opinion poll for the establishment of a bioethanol plant utilizing local resources such as the cultivation of sweet sorghum and the zeolite deposits was held. The simple random sampling was applied for the estimation of the sample size and a face-to-face interviewing and filling in of the forms of a questionnaire was conducted. The views of the local population for the establishment of a bioethanol plant utilizing local resources are mostly affirmative.

The establishment of a bioethanol production industrial unit using sweet sorghum as a plant raw material in the municipality of Trigono will upgrade the greater region of Evros prefecture. It is a common conviction that the bioethanol plant will constitute an important attraction pole for incoming planters considering the fact of the reduced taxes which will be paid by those who will take part in the bioethanol production program and the relatively higher bounties. This industrial unit will contribute to the local development as it can provide jobs for a great part of the rural population for the cultivation of sweet sorghum. This is based on the fact that the bioethanol plant will be able to absorb the total amount of the sweet sorghum production of a cultivating area that reaches at the most 55,971 acres. It was estimated that 44,778-55,971 acres of land should be cultivated with sweet sorghum for a satisfactory production of bioethanol in a bioethanol plant in the order of 120,000-150,000 tons/year.

The respondents have been informed about the beneficial properties of clinoptilolite as a soil ameliorative mainly by the Agricultural Cooperative and the Local Prefecture and the majority of them (78\%) are willing to use it in their crops and especially in the cultivation of sweet sorghum expecting a higher yield on their production. The general belief of the respondents was that they needed support from the state. The excavation of clinoptilolite and its use as a soil ameliorative generally and specifically in order to 
improve the yield of the cultivation of the sweet sorghum which will be used as a raw material for the production of bioethanol in the bioethanol plant that will be built in the area will bring a boost to the local economy.

Furthermore, the authors built a fuzzy logic system, namely defined inputs and outputs, created membership functions, created rules and the authors simulated the results of Rule Viewer and Surface Viewer of a fuzzy inference system. The Surface Viewer shows a high value of annual production of bioethanol for large cultivating area with sweet sorghum and full time of plant operation and a medium (average) annual production of bioethanol for medium cultivating area with sweet sorghum. By the Rule Viewer is shown that the input value for "cultivating area with sweet sorghum" is 46,600 acres and the input value for "time of plant operation" is 12 hours and they correspond to an output value for "annual production of bioethanol" equal to 125,000 tons of bioethanol. This constitutes the optimum solution in the problem which was found by using of the Fuzzy Logic Toolbox of Matlab. In other words, the bioethanol plant absorbing the sweet sorghum production of a cultivating area of 46,600 acres and operating 12 hours/day would produce 125,000 tons of bioethanol annually.

\section{Acknowledgments}

The author would like to thank the reviewers of this paper for their valuable comments and contribution to the improvement of the manuscript.

\section{References}

[1] Vakakis, F. 2007. "Energy Crops and Agricultural Income." Agriculture-Stock Breeding 8: 34-45.

[2] Reddy, B., and Reddy, P. 2003. "Sweet Sorghum: Characteristics and Potential." International Sorghum and Millets Newsletter 44: 26-32.

[3] Newspaper. 2014. "Ethanol's Production in the World." Newspaper 27 (January): 30-32.

[4] Zhang, C., Xie, G., Li, S., Ge, L., and He, T. 2010. "The Productive Potentials of Sweet Sorghum Ethanol in
China." Applied Energy 87 (7): 2360-2368.

[5] Woods, J. 2001. "The Potential for Energy Production Using Sweet Sorghum in Southern Africa." Energy for Sustainable Development 5 (1): 31-38.

[6] N. S. S. G. 2014. "Results of a Census about Population and Households." National Statistical Service of Greece 4 (2): 142-157.

[7] Hall, A., Stamatakis, M., and Walsh, J. 2000. "The Pentalofos Zeoletic Tuff Formation: A Giant Ion-exchange Column." Annales Geologiques Des Pays Helleniques 38: 98-112.

[8] Filippidis, A., Apostolidis, N., Paragios, I., and Filippidis, S. 2008. "Zeolites Clean Up." Industrial Minerals 48: 68-71.

[9] Stamatakis, M., Hall, A., and Hein, J. 1996. "The Zeolite Deposits of Greece." Mineralium Deposita Springer-verlag 31: 473-481.

[10] Barbieri, M., Castorina, F., Masi, U., Garbarino, C., Nicoletti, M., Kassoli-Fournaraki, A., et al. 2001. "Geochemical and Isotopic Evidence for the Origin of Rhyolites from Petrota (Northern Thrace, Greece) and Geodynamic Significance." Chemie Der Erde-geochemistry 61: 13-29.

[11] Kirov, G., Filippidis, A., Tsirambidis, A., Tzvetanov, R., and Kassoli-Fournaraki, A. 1989. "Zeolite-bearing Rocks in Petrota Area, Greece." Geologica Rhodopica 2: 500-511.

[12] Stamatakis, M., Hall, A., Lutat, U., and Walsh, J. 1998. "Mineralogy, Origin and Commercial Value of the Zeolite-rich Tuffs in the Petrota-pentalofos Area, Evros County, Greece." Estudios Geologicos-madrid 54 (2): 3-15.

[13] Filippidis, A. 2010. "Environmental, Industrial and Agricultural Applications of Hellenic Natural Zeolite." Hellenic Journal of Geosciences 45: 91-100.

[14] Vogiatzis, D., Kantiranis, N., Filippidis, A., Tzamos, E., and Sikalidis, C. 2012. "Hellenic Natural Zeolite as a Replacement of Sand in Mortar: Mineralogy Monitoring and Evaluation of Its Influence on Mechanical Properties." Geosciences 2: 298-307.

[15] Wilson, G., Pond, W., and Mumphton, F. 1984. Zeo-agriculture, Use of Natural Zeolites in Agriculture and Aquaculture. New York: International Committee on Natural Zeolites, Brockport.

[16] Freese, F. 1962. Elementary Forest Sampling. In Agricultural Handbook. USA: USD Epartment of Agriculture, Forest Service.

[17] Matis, K. 1988. Forest Sampling. Thessaloniki: Aristotle University Publications.

[18] Damianou, H. 1995. Sampling Methodology. Techniques and Applications. Athens: The Ethra Press Co.. 


\section{Resources and a Fuzzy Inference System}

[19] Johnson, E. 2000. Forest Sampling Desk Reference. Florida: CRC Press.

[20] Dalianis, K. 1972. Designing and Analysis of Experiments. Athens: Agricultural University Publications.

[21] Filias, V. 1977. An Introduction to the Methodology and Techniques of Social Research. Athens: The Gutenberg Press Co.

[22] Daoutopoulos, G. 1994. Methodology of Social Research in the Rural Area. Thessaloniki: Aristotle University Publications.

[23] Siardos, G. 1997. Methodology of Agricultural Sociological Research. Thessaloniki: The Ziti Press Co..

[24] Javeau, C. 1996. The Research by Using of a Questionnaire. Athens: The Typothito Press Co..
[25] Bell, J. 1997. Methodological Planning of Social Research. Athens: The Gutenberg Press Co..

[26] Berkan, R., and Trubatch, S. 1997. Fuzzy System Design Principles. New York: Wiley-IEEE Press.

[27] Negnevitsky, M. 2005. Artificial Intelligence. A Guide to Intelligent Systems. Second Edition. Essex, England: Addison-wesley, Pearson Education Limited.

[28] Nguyen, H., and Walker, E. 2006. A First Course in Fuzzy Logic. Boca Raton: CRC Press Taylor and Francis Group.

[29] Sivanandam, S., Sumathi, T., and Deepa, L. 2007. Introduction to Fuzzy Logic Using Matlab. Berlin Heidelberg: Springer.

[30] Ross, T. 2010. Fuzzy Logic with Engineering Applications. Third Edition. Chichester, UK: Wiley. 